Fetal Diagnosis and Therapy
Fetal Diagn Ther 2010;27:8-13

DOI: $\underline{10.1159 / 000258048}$
Received: June 29, 2009

Accepted after revision: September 15, 2009

Published online: November 11, 2009

\title{
Prognostic Role of Uterine Artery Doppler in Patients with Preeclampsia
}

\author{
Eva Meler Francesc Figueras Raquel Mula Fatima Crispi Mar Benassar \\ Olga Gómez Eduard Gratacós
}

Department of Maternal-Fetal Medicine, ICGON, Fetal and Perinatal Medicine Research Group (IDIBAPS) and Center of Biomedical Research on Rare Diseases (CIBER-ER), Hospital Clinic, University of Barcelona,

Barcelona, Spain

\section{Key Words}

Preeclampsia - Uterine artery Doppler - Perinatal outcome, adverse

\begin{abstract}
Objectives: To evaluate the predictive capacity of umbilical, cerebral and uterine artery Doppler in women admitted for preeclampsia (PE). Methods: 190 consecutive singleton pregnancies admitted with PE were included. Umbilical, cerebral and uterine artery Dopplers were performed. The association with adverse perinatal outcome was evaluated from $2 \times 2$ tables and multivariately by logistic regression. Results: A total of 82 (43\%) women had an abnormal uterine artery Doppler on admission, being more prevalent in early-onset ( $<32$ weeks) than in the late-onset PE (62 vs. $27 \%$, $p<0.05$ ). In both early- and late-onset forms, uterine artery Doppler showed a greater capacity than umbilical and middle cerebral artery Doppler for predicting adverse perinatal outcome. Conclusion: Uterine artery Doppler was the best predictive parameter for perinatal outcome in pregnancies with PE and may be included as a primary surveillance test.
\end{abstract}

Copyright $\odot 2009$ S. Karger AG, Basel
(C) 2009 S. Karger AG, Basel

$1015-3837 / 10 / 0271-0008 \$ 26.00 / 0$

Fax +4161306 1234

E-Mail karger@karger.ch

www.karger.com
Accessible online at: www.karger.com/fdt

\section{Introduction}

Preeclampsia (PE) affects about $2-3 \%$ of pregnancies and is a major contributor to maternal mortality with an estimated 50,000 deaths/year worldwide [1]. PE is also associated with increased perinatal morbidity [2] and mortality [3].

In recent years, it has been established that early- and late-onset $\mathrm{PE}$ are associated with different biochemical and clinical features [4]: whereas the early-onset form is almost invariably associated with placental insufficiency and growth restriction, the late-onset form is more prevalent and, in general, placental involvement is minimally present. In patients with early-onset PE, expectant management improves neonatal outcome in selected cases, decreasing neonatal care intensive unit admittance and neonatal respiratory distress $[5,6]$. Also in selected cases, mild PE could be managed in an outpatient regimen until term [7], providing a reassuring maternal and fetal assessment. While the criteria of maternal risk on which the selection of cases for expectant management could be based are well defined $[7,8]$, fetal criteria are not as well established.

Umbilical artery (UA) and middle cerebral artery (MCA) Dopplers are standard parameters in the manage-

Francesc Figueras

Department of Maternal-Fetal Medicine, Hospital Clinic

ES-08036 Barcelona (Spain)

Tel. +34932 275 600, Fax +34932 275605

E-Mail ffiguera@clinic.ub.es 
ment of pregnancies at risk of placental insufficiency [9]. Uterine artery (UtA) Doppler has been widely studied for the prediction of $\mathrm{PE}$ and intrauterine growth restriction, reflecting the involvement of a defective trophoblastic invasion. However, it has scarcely been evaluated as a prognostic tool at the onset of PE [10-12]. Only recently, it has been reported that women with late-onset PE show a higher risk of perinatal complications if uterine resistance is increased [13]. Also, preeclamptic women with abnormal uterine flow are at higher risk of recurrence during their next pregnancy [14]. The role of UtA Doppler in identifying pregnancies at risk of fetal morbidity in both early and late forms of PE has not been investigated. It is also unknown if its prediction capacity is superior to that of UA and MCA Doppler.

This study aimed to evaluate the prediction capacity of UA, MCA and UtA Doppler in women admitted for PE.

\section{Material and Methods}

\section{Population}

Between January 2002 and December 2008 a cohort was created of 190 women with singleton pregnancies and PE who were admitted to a referral hospital in Barcelona (Spain). PE was defined according to the International Society Study of Hypertension in Pregnancy as a resting blood pressure of $\geq 140 / 90 \mathrm{~mm} \mathrm{Hg}$ on 2 occasions at least $4 \mathrm{~h}$ apart, and the presence of proteinuria $(\geq 0.3 \mathrm{~g} / \mathrm{dl})$ or a $2+$ urine dipstick, beyond 20 weeks of pregnancy in previously normotensive women.

\section{Measurements}

On admission, all women underwent blood and urine workup according to current recommendations $[7,8]$. Doppler examination was also performed on hospital admission using a Voluson 730 Pro or Voluson 730 Expert (GE Medical Systems, Milwaukee, Wisc., USA) equipment. All the scans were performed by 1 of 6 experienced observers. UtA Doppler was carried out by identifying the vessel in an oblique scan with the sample volume distal to the crossing with the external iliac artery. Pulsatility indexes (PIs) of the left and right arteries were measured and the mean PI was calculated. The UA Doppler flow spectrum was recorded from a free-floating portion of the umbilical cord. The MCA Doppler was recorded in a transverse view of the fetal brain, with the Doppler gate placed on the vessel about $1 \mathrm{~cm}$ distal to the circle of Willis. In all these vessels, the pulsed Doppler gate was placed over the whole width of the vessel once it had been ensured that the angle was $<30^{\circ}$. Angle correction was then applied and the signal updated until 3 similar consecutive waveforms were obtained. Gestational age was calculated according to the crownrump length at first trimester ultrasound [15]. The UtA Doppler investigation on admission and the last UA and MCA Doppler investigation within 1 week before delivery were considered for the analysis.

Prognostic Role of Uterine Artery

Doppler in Patients with Preeclampsia

\section{Definitions}

Early PE was defined as that diagnosed before 32.0 weeks. Severe $\mathrm{PE}$ was defined as a blood pressure of $\geq 160 / 110 \mathrm{~mm} \mathrm{Hg}$ on 2 or more determinations, proteinuria of $\geq 5 \mathrm{~g} / 24 \mathrm{~h}$ or the presence of maternal complications, including eclampsia and other neurological manifestations, HELLP syndrome (lactate dehydrogenase $>600 \mathrm{IU} / 1$, aspartate transaminase $>62 \mathrm{IU} / 1$, platelet count $\left.\left(10^{9} / 1\right)<100,000\right)$, acute renal failure defined as creatinine $>1.2$ $\mathrm{g} / \mathrm{dl}$, subcapsular hepatic hematoma, pulmonary edema and the presence of disseminated intravascular disease. Small-for-gestational age (SGA) was defined as a birth weight $<10$ th centile according to local customized curves [16]. Adverse perinatal outcome was defined as the presence of at least one of the following: fetal or neonatal demise, acidosis at birth (UA pH $<7.10$ and base excess $>12 \mathrm{mEq} / \mathrm{l}$ ), 5-min Apgar score $<7$, and admission to the neonatal intensive unit for more than 10 days.

\section{Management}

Magnesium sulfate seizure prophylaxis was administered to all women with severe PE, as well as first and second-line antihypertensive therapy with labetalol and hydralacine, respectively, when blood pressure was persistently $\geq 160 / 110 \mathrm{~mm} \mathrm{Hg}$. Corticosteroid therapy for fetal lung maturity was administered to all pregnancies less than 34 weeks of gestational age. During admission, maternal blood pressure was recorded several times per day and laboratory testing at least twice a week. Fetal assessment was performed by daily fetal heart rate monitoring and Doppler at least every 3 days. Indications for delivery were severe PE beyond 32 weeks once pulmonary maturation was completed, uncontrollable blood pressure, maternal complications (defined above), abruptio placentae or decelerative fetal heart rate $(>5$ decelerations of more than 30 beats/min from basal line in $30 \mathrm{~min}$ ). In addition, beyond 28 weeks indications for delivery also included UA Doppler with absent reversed end-diastolic velocities or persistent $(>12 \mathrm{~h}$ apart) ductus venosus Doppler with absent or reversed atrial flow. Women without severity criteria [7] were discharged and outpatient management with weekly fetal and maternal assessment was performed. In cases with mild PE, delivery was induced after 37 weeks.

\section{Statistical Analyses}

Doppler parameters were transformed into $\mathrm{z}$ values for gestational age $[17,18]$. Best cutoffs were chosen by means of receiver operator characteristics (ROC) curve analyses. Sensitivity, specificity and positive and negative likelihood ratios (LHRs) for the prediction of adverse outcome were calculated. Multivariate analysis for the occurrence of adverse perinatal outcome was performed by logistic regression. MedCalc 8.0 (MedCalc Software, Belgium) and SPSS 14.0 (SPSS Inc., USA) were used for the statistical analyses.

\section{Results}

Table 1 details the basal characteristics of the study population at admission. In $85 \%(162 / 190)$ of the patients, the criteria of severity were met; and in $44 \%(84 / 190)$ the clinical onset was before 32 weeks. Among the early-on- 
set cases, 96\% fulfilled the criteria of severity, whereas only $76 \%$ of the late-onset cases fulfilled them ( $\mathrm{p}<$ 0.05).

Table 2 depicts the perinatal outcome. SGA was found in 120 neonates $(63.2 \%)$, with a higher incidence in earlyonset PE (85 vs. $44 \%, \mathrm{p}<0.05)$. A total of $51(26.8 \%)$ infants had adverse perinatal outcomes, including non-exclusively 12 perinatal deaths, 9 cases with 5-min Apgar score of $<7,21$ cases of UA pH $<7.10$, and 20 cases that required admission to the neonatal intensive care unit for more than 10 days. Early-onset cases showed a nonsignificant trend to a higher incidence of adverse outcome (33.3 vs. $21.4 \%, \mathrm{p}=0.06$ ).

ROC curve analysis showed that whereas the area under the curve was 0.69 (95\% CI $0.60-0.78$; $p<0.001$ ) for UtA PI, it was $0.59(95 \%$ CI $0.50-0.69 ; \mathrm{p}=0.06)$ and 0.58 (95\% CI $0.48-0.68 ; \mathrm{p}=0.09$ ) for UA PI and MCA PI, respectively. The best cutoff for UtA PI was the 97.5th centile, and the 95th centile for UA PI and MCA PI. Overall, a total of $82(43 \%)$ women had UtA PI $>97.5$ th centile on admission. While this proportion was $62 \%(54 / 87)$ among early-onset PE, it was $27 \%(28 / 103)$ in cases with late-onset. Table 3 details the performance of Doppler parameters in predicting adverse perinatal outcome in both early- and late-onset clinical forms. Importantly, in both early- and late-onset forms, abnormal UtA Doppler showed a higher sensitivity and greater capacity for ruling in (+LHR) and out (-LHR) the occurrence of adverse outcome.

Multivariate regression analysis including standard severity criteria of PE showed (table 4) that abnormal UtA was the only parameter that significantly and independently predicted adverse perinatal outcome, with an OR of 4.17 (95\% CI 1.97-8.81; p < 0.001). On stratification for early- and late-onset clinical forms, the ORs were 3.34 (95\% CI 1.05-10.6; $\mathrm{p}=0.04)$ and 5.18 (95\% CI 1.63-16.47; $\mathrm{p}=0.005)$, respectively.

\section{Discussion}

Our study demonstrates that UtA Doppler on admission for PE is superior to UA and MCA Doppler in identifying those cases at higher risk of adverse perinatal outcome. In addition, we found that none of the standard severity criteria for PE were significantly associated with this adverse outcome.

UtA Doppler is a validated noninvasive surrogate of trophoblastic invasion [19] and placental perfusion [20]. Thus, neonates of preeclamptic women with abnormal

Table 1. Characteristics of the study population

$\begin{array}{lc}\text { Basal characteristics } & \\ \text { Maternal age, years } & 31.5(5.2) \\ \text { Body mass index } & 26.9(7) \\ \text { Primiparity, \% } & 62.6 \\ \text { Smoking, \% } & 22 \\ \text { Risk factors for preeclampsia } & \\ \quad \text { Body mass index >30, \% } & 38 \\ \quad \text { Diabetes mellitus, \% } & 2.6 \\ \quad \text { Autoimmune disease, \% } & 3.2 \\ \text { Thrombophilia, \% } & 3.7 \\ \quad \text { Dyslipidemia, \% } & 4.7 \\ \text { Previous preeclampsia, \% } & 8.4\end{array}$

Characteristics on admission

Gestational age at onset, weeks 32.4 (4)

Early-onset preeclampsia (<32 weeks), \% 44

Diastolic blood pressure, mm Hg 105 (10)

Systolic blood pressure, $\mathrm{mm} \mathrm{Hg} \quad 172(20)$

24-hour proteinuria, g $2.3(2.5)$

Severity criteria, \% 85

Data expressed as mean (standard deviation) or proportions.

Table 2. Perinatal outcome of the study population

Gestational age at delivery, weeks

Admission to delivery interval, days

Birth weight, $g$

Emergent CS for fetal distress, \%

Admission to NICU for $>7$ days, $\%$

SGA, \%

Acidosis at birth, \%

5-Min Apgar score $<7, \%$

Perinatal mortality, \%

Stillbirth, \%

Neonatal death, \%

33.5
9
1,833
20
20
63.1
11.3
4.8
6.3
2.1
4.3

Data expressed as mean (standard deviation) or proportions. $\mathrm{CS}=$ Cesarean section; NICU $=$ neonatal intensive care unit; $\mathrm{SGA}=$ small-for-gestational age.
UtA Doppler are likely to have been exposed to more severe intrauterine hypoxia secondary to placental insufficiency, which explains the association with adverse outcome. The fact that UtA Doppler was more predictive than UA Doppler could speculatively be explained because the latter has been demonstrated to become abnormal only in advanced stages of placental dysfunction [21, 22]. Also, regional brain perfusion studies in IUGR fetuses showed that brain hypoxia is present long before 
Table 3. Prediction of Doppler parameters for adverse perinatal outcome

\begin{tabular}{lccccccc}
\hline & Se & Sp & +LHR & -LHR & OR & $95 \%$ CI & p \\
\hline Overall & & & & & & & \\
$\quad$ Abnormal UtA & 67 & 65 & 1.93 & 0.51 & 3.80 & $1.92-7.48$ & $<0.001$ \\
$\quad$ Abnormal UA & 45 & 63 & 1.23 & 0.87 & 1.42 & $0.74-2.72$ & 0.29 \\
$\quad$ Abnormal MCA & 47 & 65 & 1.33 & 0.82 & 1.63 & $0.85-3.13$ & 0.14 \\
Early-onset & & & & & & & \\
$\quad$ Abnormal UtA & 79 & 47 & 1.48 & 0.44 & 3.34 & $1.18-9.41$ & 0.02 \\
$\quad$ Abnormal UA & 62 & 41 & 1.06 & 0.92 & 1.16 & $0.46-2.88$ & 0.76 \\
$\quad$ Abnormal MCA & 62 & 52 & 1.29 & 0.73 & 1.75 & $0.71-4.36$ & 0.23 \\
Late-onset & & & & & & & \\
$\quad$ Abnormal UtA & 50 & 79 & 2.38 & 0.63 & 3.77 & $1.40-10.15$ & 0.06 \\
$\quad$ Abnormal UA & 23 & 79 & 1.08 & 0.98 & 1.1 & $0.35-3.43$ & 0.86 \\
Abnormal MCA & 27 & 74 & 1.05 & 0.98 & 1.07 & $0.37-3.1$ & 0.9 \\
\hline
\end{tabular}

$\mathrm{Se}=$ Sensitivity; $\mathrm{Sp}=$ specificity; $\mathrm{LHR}=$ likelihood ratio $\mathrm{CI}=$ confidence interval; $\mathrm{OR}=$ odds ratio; $\mathrm{UtA}=$ uterine artery; $\mathrm{UA}=$ umbilical artery; $\mathrm{MCA}=$ middle cerebral artery.
Table 4. Regression analysis of severity criteria for the prediction of adverse perinatal outcome

\begin{tabular}{lllc}
\hline & OR & $95 \%$ CI & $\mathrm{p}$ \\
\hline Blood pressure $\geq 160 / 110 \mathrm{~mm} \mathrm{Hg}$ & 0.72 & $0.35-1.49$ & 0.37 \\
Prodromic neurological symptoms & 1.53 & $0.72-3.23$ & 0.27 \\
AST $>62 \mathrm{UI} / \mathrm{l}$ & 0.6 & $0.19-1.86$ & 0.37 \\
$\mathrm{LDH}>600 \mathrm{mg} / \mathrm{dl}$ & 0.94 & $0.38-2.29$ & 0.88 \\
Creatinine $>1.2 \mathrm{mg} / \mathrm{dl}$ & 0.84 & $0.07-10.55$ & 0.89 \\
24-Hour proteinuria $>5 \mathrm{~g} / \mathrm{dl}$ & 1.67 & $0.57-4.94$ & 0.35 \\
Platelet count $\left(10^{9} / \mathrm{l}\right)<100,000 / 1$ & 0.50 & $0.14-1.77$ & 0.28 \\
SGA & 1.12 & $0.52-2.42$ & 0.77 \\
Abnormal mean UtA PI & 4.17 & $1.97-8.81$ & $<0.001$ \\
Abnormal UA PI & 1.65 & $0.55-2.75$ & 0.38 \\
Abnormal MCA PI & 1.73 & $0.87-2.59$ & 0.25 \\
\hline
\end{tabular}

$\mathrm{UtA}=$ Uterine artery; $\mathrm{PI}=$ pulsatility index; $\mathrm{UA}=$ umbilical artery; $\mathrm{MCA}=$ middle cerebral artery; AST = aspartate transaminase; $\mathrm{LDH}=$ lactate dehydrogenase; SGA = small-for-gestational age; $\mathrm{CI}=$ confidence interval.

significant changes in MCA are observed [23]. In keeping with this, Geerts and Odendaal [24] found that in severe PE, umbilical and cerebral Doppler parameters were not associated with adverse outcome, once adjusted for fetal size. On the contrary, our multivariate analysis that included SGA as a covariate confirmed the significant and independent value of UtA Doppler in predicting adverse outcome. In a group of 115 preeclamptic women, Simanaviciute and Gudmundsson [25] found that cerebral to uterine Doppler better predicted the necessity to deliver prematurely than abnormal Doppler alone in either the UA or UtA. However, the authors did not report these results separately for early- and late-onset cases. Besides the interval between examination and delivery (mean 4.5 weeks) prevents strong conclusions from being drawn. In line with our results, Ghi et al. [13] found in late-onset PE that abnormal UtA was strongly associated with adverse perinatal outcome, but in this study the comparison of this predictive capacity with that of UA and MCA Doppler was not addressed.

The severity of PE is defined by biochemical and clinical maternal parameters [7], being essentially focused on maternal wellbeing. Interestingly, a survey including 18 experts [26] aimed at identifying tests (among 33 tests which included items of history, examination, and investigations) that could be clinically relevant in predicting maternal and fetal complications in women with PE, revealed that 'ultrasound including Doppler studies', unspecifically, was not rated among the potentially most useful predictors. Consistent with our findings, some previous studies $[27,28]$ have also suggested that presumed intrauterine stress reflected by the severity of maternal disease did not accurately predict neonatal outcome. It is therefore, of importance to define parameters that could better predict perinatal outcome. In our study, abnormal UtA Doppler at the onset of PE was the only parameter that significantly and independently predicted adverse perinatal outcome.

In keeping with the concept that early- and late-onset $\mathrm{PE}$ are associated with different biochemical and clinical features [4], we have found that while more than half 
of the early-onset cases of PE had an abnormal UtA Doppler, only one quarter of the cases of late-onset had this Doppler sign. These findings conferred to the UtA Doppler a different potential role for each clinical form. In early $\mathrm{PE}$, where efforts are made to prolong the pregnancy to allow fetal maturation, the UtA performs better in ruling out the occurrence adverse outcome, allowing the safe prolongation of pregnancy. Our results do not support including abnormal UtA as an indication for early delivery. On the other hand, in late-onset PE, UtA Doppler is better at defining at-risk fetuses in whom the recommended outpatient management for mild PE [7] could pose an unnecessary risk. Ghi et al. [13] have recently reported how in late-onset PE UtA accounts for most cases of adverse outcome.

One of the limitations of our study is that most cases (85\%) met the criteria of severity and it could be argued that our sample represents a population of preeclamptic women referred to a tertiary hospital rather than the overall population of preeclamptic women. This could have increased the sensitivity, specificity and LHRs of all the diagnostic tests, but could not explain the differences between them. Another limitation is that second-trimester Doppler was not available for analysis. This could have enabled knowing whether preeclamptic women with abnormal Doppler at onset correspond to those with abnormal flow in the second trimester. This could mean that an adverse outcome secondary to PE could be predicted earlier by second-trimester Doppler. However, Soregaroli et al. [29] reported that about half of the women with abnormal UtA Doppler at 24 weeks had normalization of Doppler indices by 34 weeks. As the proportion of abnormal Doppler in the second trimester [30] is the same as the proportion found in our study at clinical onset, one could speculatively conclude that some women convert from normal to abnormal and vice versa during the third trimester.

Our findings contribute to the premises for future studies evaluating management strategies based on UtA Doppler results at the clinical onset of PE.

\section{References}

1 World Health Organization: Estimates of Maternal Mortality: A New Approach by WHO and UNICED. Geneva, World Health Organization, 1996.

2 Iams JD, Goldenberg RL, Mercer BM, et al: The Preterm Prediction Study: recurrence risk of spontaneous preterm birth. National Institute of Child Health and Human Development Maternal-Fetal Medicine Units Network. Am J Obstet Gynecol 1998;178:10351040.

-3 Gardosi J, Kady SM, McGeown P, Francis A, Tonks A: Classification of stillbirth by relevant condition at death (ReCoDe): population based cohort study. BMJ 2005;331:11131117.

-4 Crispi F, Dominguez C, Llurba E, MartinGallan P, Cabero L, Gratacos E: Placental angiogenic growth factors and uterine artery Doppler findings for characterization of different subsets in preeclampsia and in isolated intrauterine growth restriction. Am J Obstet Gynecol 2006;195:201-207.

5 Sibai BM, Mercer BM, Schiff E, Friedman SA: Aggressive versus expectant management of severe preeclampsia at 28 to 32 weeks' gestation: a randomized controlled trial. Am J Obstet Gynecol 1994;171:818822.

-6 Odendaal HJ, Pattinson RC, Bam R, Grove D, Kotze TJ: Aggressive or expectant management for patients with severe preeclampsia between 28-34 weeks' gestation: a randomized controlled trial. Obstet Gynecol 1990;76:1070-1075.
7 Report of the National High Blood Pressure Education Program Working Group on High Blood Pressure in Pregnancy. Am J Obstet Gynecol 2000;183:S1-S22.

8 Scherjon S, Briet J, Oosting H, Kok J: The discrepancy between maturation of visualevoked potentials and cognitive outcome at five years in very preterm infants with and without hemodynamic signs of fetal brainsparing. Pediatrics 2000;105:385-391.

-9 Baschat AA: Integrated fetal testing in growth restriction: combining multivessel Doppler and biophysical parameters. Ultrasound Obstet Gynecol 2003;21:1-8.

10 Frusca T, Soregaroli M, Platto C, Enterri L, Lojacono A, Valcamonico A: Uterine artery velocimetry in patients with gestational hypertension. Obstet Gynecol 2003;102:136140.

11 Li H, Gudnason H, Olofsson P, Dubiel M, Gudmundsson S: Increased uterine artery vascular impedance is related to adverse outcome of pregnancy but is present in only onethird of late third-trimester pre-eclamptic women. Ultrasound Obstet Gynecol 2005; 25:459-463.

12 Hernandez-Andrade E, Brodszki J, Lingman G, Gudmundsson S, Molin J, Marsal K: Uterine artery score and perinatal outcome. Ultrasound Obstet Gynecol 2002;19:438-442.

13 Ghi T, Youssef A, Piva M, et al: The prognostic role of uterine artery Doppler studies in patients with late-onset preeclampsia. Am J Obstet Gynecol 2009;201:36.e1-36.e5.
14 Gudnasson HM, Dubiel M, Gudmundsson S: Preeclampsia - abnormal uterine artery Doppler is related to recurrence of symptoms during the next pregnancy. J Perinat Med 2004;32:400-403.

15 Robinson HP, Fleming JE: A critical evaluation of sonar 'crown-rump length' measurements. Br J Obstet Gynaecol 1975;82:702710 .

-16 Figueras F, Meler E, Iraola A, et al: Customized birthweight standards for a Spanish population. Eur J Obstet Gynecol Reprod Biol 2008;136:20-24.

-17 Arduini D, Rizzo G: Normal values of Pulsatility Index from fetal vessels: a cross-sectional study on 1556 healthy fetuses. J Perinat Med 1990;18:165-172.

18 Gomez O, Figueras F, Fernandez S, et al: Reference ranges for uterine artery mean pulsatility index at 11-41 weeks of gestation. Ultrasound Obstet Gynecol 2008;32:128-132.

19 Lin S, Shimizu I, Suehara N, Nakayama M, Aono T: Uterine artery Doppler velocimetry in relation to trophoblast migration into the myometrium of the placental bed. Obstet Gynecol 1995;85:760-765.

20 Kaar K, Jouppila P, Kuikka J, Luotola H, Toivanen J, Rekonen A: Intervillous blood flow in normal and complicated late pregnancy measured by means of an intravenous ${ }^{133} \mathrm{Xe}$ method. Acta Obstet Gynecol Scand 1980;59:7-10. 
21 Morrow RJ, Adamson SL, Bull SB, Ritchie JW: Effect of placental embolization on the umbilical arterial velocity waveform in fetal sheep. Am J Obstet Gynecol 1989;161:10551060.

22 Thompson RS, Stevens RJ: Mathematical model for interpretation of Doppler velocity waveform indices. Med Biol Eng Comput 1989;27:269-276.

23 Hernandez-Andrade E, Figueroa-Diesel H, Jansson T, Rangel-Nava H, Gratacos E: Changes in regional fetal cerebral blood flow perfusion in relation to hemodynamic deterioration in severely growth-restricted fetuses. Ultrasound Obstet Gynecol 2008;32:7176.
24 Geerts L, Odendaal HJ: Severe early onset pre-eclampsia: prognostic value of ultrasound and Doppler assessment. J Perinatol 2007;27:335-342.

25 Simanaviciute D, Gudmundsson S: Fetal middle cerebral to uterine artery pulsatility index ratios in normal and pre-eclamptic pregnancies. Ultrasound Obstet Gynecol 2006;28:794-801.

26 Thangaratinam S, Ismail K, Sharp S, et al: Prioritisation of tests for the prediction of preeclampsia complications: a Delphi survey. Hypertens Pregnancy 2007;26:131-138.

27 Witlin AG, Saade GR, Mattar F, Sibai BM: Predictors of neonatal outcome in women with severe preeclampsia or eclampsia between 24 and 33 weeks' gestation. Am J Obstet Gynecol 2000;182:607-611.
28 Nisell H, Palm K, Wolff K: Prediction of maternal and fetal complications in preeclampsia. Acta Obstet Gynecol Scand 2000;79:1923.

29 Soregaroli M, Valcamonico A, Scalvi L, Danti L, Frusca T: Late normalisation of uterine artery velocimetry in high risk pregnancy. Eur J Obstet Gynecol Reprod Biol 2001;95: 42-45.

30 Gomez O, Figueras F, Martinez JM, et al: Sequential changes in uterine artery blood flow pattern between the first and second trimesters of gestation in relation to pregnancy outcome. Ultrasound Obstet Gynecol 2006;28: 802-808. 